\title{
Guidelines for the clinical management of familial adenomatous polyposis (FAP)
}

\author{
H F A Vasen, ${ }^{1}$ G Möslein, ${ }^{2}$ A Alonso, ${ }^{3}$ S Aretz, ${ }^{4}$ I Bernstein, ${ }^{5}$ L Bertario, ${ }^{6}$ I Blanco, ${ }^{7}$ \\ S Bülow, ${ }^{8} \mathrm{~J}$ Burn, ${ }^{9} \mathrm{G}$ Capella, ${ }^{10} \mathrm{C}$ Colas, ${ }^{11} \mathrm{C}$ Engel, ${ }^{12}$ I Frayling, ${ }^{13}$ W Friedl, ${ }^{4} \mathrm{~F} \mathrm{~J}$ Hes, ${ }^{14}$ \\ S Hodgson, ${ }^{15} \mathrm{H}$ Järvinen, ${ }^{16} \mathrm{~J}$-P Mecklin, ${ }^{17} \mathrm{P}$ Møller, ${ }^{18} \mathrm{~T}$ Myrhøø, ${ }^{5} \mathrm{~F}$ M Nagengast, ${ }^{19}$ \\ Y Parc, ${ }^{20} \mathrm{R}$ Phillips, ${ }^{21}$ S K Clark, ${ }^{21} \mathrm{M}$ Ponz de Leon, ${ }^{22}$ L Renkonen-Sinisalo, ${ }^{16}$ \\ J R Sampson, ${ }^{13}$ A Stormorken, ${ }^{23}$ S Tejpar, ${ }^{24}$ H J W Thomas, ${ }^{25}$ J Wijnen $^{14}$
}

For numbered affiliations see end of article

\section{Correspondence to:}

Dr H F A Vasen, Department of

Gastroenterology and

Hepatology, Leiden University

Medical Centre, Rijnsburgerweg

10, 2333 AA Leiden, The

Netherlands; hfavasen@stoet.nl

HFAV and GM contributed equally.

Revised 29 November 2007 Accepted 4 December 2007 Published Online First

14 January 2008

\section{ABSTRACT}

Background: Familial adenomatous polyposis (FAP) is a well-described inherited syndrome, which is responsible for $<1 \%$ of all colorectal cancer (CRC) cases. The syndrome is characterised by the development of hundreds to thousands of adenomas in the colorectum. Almost all patients will develop CRC if they are not identified and treated at an early stage. The syndrome is inherited as an autosomal dominant trait and caused by mutations in the APC gene. Recently, a second gene has been identified that also gives rise to colonic adenomatous polyposis, although the phenotype is less severe than typical FAP. The gene is the MUTYH gene and the inheritance is autosomal recessive. In April 2006 and February 2007, a workshop was organised in Mallorca by European experts on hereditary gastrointestinal cancer aiming to establish guidelines for the clinical management of FAP and to initiate collaborative studies. Thirty-one experts from nine European countries participated in these workshops. Prior to the meeting, various participants examined the most important management issues according to the latest publications. A systematic literature search using Pubmed and reference lists of retrieved articles, and manual searches of relevant articles, was performed. During the workshop, all recommendations were discussed in detail. Because most of the studies that form the basis for the recommendations were descriptive and/or retrospective in nature, many of them were based on expert opinion. The guidelines described herein may be helpful in the appropriate management of FAP families. In order to improve the care of these families further, prospective controlled studies should be undertaken.

In about $5 \%$ of all cases, colorectal cancer (CRC) is associated with a dominantly or recessively inherited syndrome due to mutations in high penetrance genes. The most common syndrome is Lynch syndrome (hereditary non-polyposis colorectal cancer (HNPCC)), which is characterised by the development of CRC, endometrial cancer and various other cancers. ${ }^{1}$ The syndrome is caused by a mutation in one of the mismatch repair (MMR) genes: MLH1, MSH2, MSH6 and PMS2. Familial adenomatous polyposis (FAP) is another well-described inherited syndrome, which is responsible for $1 \%$ or less of all CRC cases. ${ }^{2}$ This syndrome is characterised by the development of hundreds to thousands of adenomas in the colorectum as well as several extracolonic manifestations.
Almost all patients will develop CRC if they are not identified and treated at an early stage. ${ }^{3}$ Approximately $8 \%$ of families with FAP display an attenuated form of FAP characterised by the development of fewer adenomas and CRC at a more advanced age. ${ }^{4}$ The syndrome, when inherited in an autosomal dominant manner, is caused by mutations in the APC gene. This gene plays a central role in the development and homeostasis of the intestine and many other tissues. Recently another polyposis gene has been identified, the MUTYH gene, in which biallelic mutations cause an autosomal recessive pattern of inheritance. ${ }^{5}$ This form of polyposis is usually referred to as $M U T Y H$-associated polyposis (MAP).

In April 2006 and February 2007, a workshop was organised for a group of European experts on hereditary gastrointestinal cancer. The main purpose was to develop guidelines for the clinical management of the most common inherited forms of CRC and to establish collaborative studies. A total of 31 experts from nine European countries participated in the workshops. These experts included clinical and molecular geneticists, surgeons, gastroenterologists and a pathologist all involved in the management of hereditary CRC. Prior to the meetings, key questions for important management issues were identified and a literature search was performed in order to address these questions and to elaborate guidelines in the light of the most recent knowledge. Here we report the outcome of the discussion with respect to FAP. Search terms included familial adenomatous polyposis (FAP), MUTYH-associated polyposis (MAP), $A P C$ gene and $M(U T) Y H$ gene. Only peer-reviewed English language articles were included. The criteria that were used for evaluation of studies and assessment of the category of evidence and strength of the recommendation are shown in table 1. During the workshop, all recommendations were discussed in detail.

\section{CHARACTERISTICS OF APC-ASSOCIATED FAP}

FAP is an autosomal dominant condition caused by $A P C$ mutations that occurs in 1 in 10000 births. ${ }^{6}$ In $15-20 \%$, the cases are "de novo" without clinical or genetic evidence of FAP in the parents. ${ }^{7}$ Recent studies indicated the presence of mosaicism in approximately $15 \%$ of such cases. ${ }^{89}$ Most patients develop hundreds of colorectal adenomas during childhood and adolescence. 
Table 1 Validity and grading of recommendations

\begin{tabular}{|c|c|c|}
\hline Category of evidence & $\begin{array}{l}\text { Grading of } \\
\text { recommendations }\end{array}$ & \\
\hline $\begin{array}{l}\text { Meta-analysis of randomised controlled } \\
\text { trials }\end{array}$ & la & A \\
\hline Randomised controlled trial & $\mathrm{lb}$ & \\
\hline $\begin{array}{l}\text { Well-designed controlled study without } \\
\text { randomisation }\end{array}$ & Ila & B \\
\hline Well designed quasi-experimental study & llb & \\
\hline Non-experimental descriptive study & III & \\
\hline Expert opinion & IV & C \\
\hline
\end{tabular}

Without surgical intervention they almost inevitably develop CRC by the mean age of $40-50$ years. A milder form of FAP (attenuated FAP, AFAP) characterised by the presence of fewer adenomas and later onset of disease is observed in approximately $8 \%$ of cases..$^{10}$ Adenomatous polyps also develop in the upper gastrointestinal tract, especially in the duodenum, and, if untreated, these progress to malignancy in approximately $5 \%$ of cases. ${ }^{11}$ Gastric fundic gland polyps and adenomas in the antrum also occur. There are a few case reports ${ }^{12}{ }^{13}$ of gastric cancer in FAP, especially from Japan and Korea, but substantial evidence of an increased risk in FAP patients from Western countries is not available. The incidence of gastric cancer in large national polyposis registries does not support the hypothesis of an increased risk, but only future large multicentre studies can clarify if the known cases represent an increased risk or mere coincidence. There is an increased risk of malignancy at other sites including the brain, thyroid and the liver. Deregulation of the APC gene has been shown to play a role in carcinogenesis in all of these tissues. Desmoid tumours occur in at least $10-15 \%$ of cases. ${ }^{14}$ Although these tumours of connective tissue are histologically benign, they can lead to life-threatening complications through their size and impingement on vital structures. Other features observed in FAP are shown in table 2.

The standard clinical diagnosis of typical/classical FAP is based on the identification of $>100$ colorectal adenomatous polyps. The clinical diagnosis of AFAP is more difficult. Recently, diagnostic criteria for AFAP have been proposed by Nielsen et $\mathrm{al}^{4}$ and by Knudsen et al (presented at the meeting of the International Society of Gastrointestinal Hereditary Tumours (InSiGHT), Yokohama 2007). According to the criteria suggested by Nielsen, there should be (1) at least two patients with 10-99 adenomas at age $>30$ years or (2) one patient with 10-99 adenomas at age $>30$ years and a first-degree relative with CRC with few adenomas; for both criteria, no family members with $>100$ adenomas before the age of 30 years. Based on a multicentre study of 196 patients, Knudsen et a ${ }^{10}$ proposed the following diagnostic criteria for AFAP: (1) a dominant mode of

Table 2 Extra-intestinal features in familial adenomatous polyposis

\begin{tabular}{ll}
\hline Benign lesions & Malignant lesions \\
\hline $\begin{array}{l}\text { Congenital hypertrophy of the retinal } \\
\text { pigmented epithelium (70-80\%) }\end{array}$ & Thyroid cancer $(2-3 \%)$ \\
$\begin{array}{l}\text { Epidermoid cysts }(50 \%) \\
\text { Osteoma (50-90\%) }\end{array}$ & Brain tumour $(<1 \%)$ \\
Desmoid tumour $(10-15 \%)$ & Hepatoblastoma $(\sim 1 \%)$ \\
Supernumerary teeth $(11-27 \%)$ & \\
Adrenal gland adenomas $(7-13 \%)$ & \\
\hline
\end{tabular}

inheritance and (2) 3-99 colorectal adenomas at age 20 or older (presented at the meeting of the International Society of Gastrointestinal Hereditary Tumours (InSiGHT), Yokohama 2007).

In more than $70 \%$ of patients with typical FAP, a mutation can be identified in the APC gene. The yield of APC gene mutations is much lower in patients with AFAP $(\sim 25 \%))^{4}$ Genetic counselling and mutation analysis should be offered to all patients with FAP. If a pathogenic mutation has been identified in the index patient, predictve testing for the mutation should be offered to the first-degree relatives. In typical FAP, family members that are found to carry the mutation should be advised to undergo periodic examination of the rectosigmoid from the early teens, and of the upper gastrointestinal tract from age 25-30 years to monitor adenoma development. The treatment of colonic polyposis consists of colectomy or proctocolectomy usually once florid polyposis has developed. The treatment of duodenal adenomas depends on the severity of the disease.

\section{SURVEILLANCE OF THE COLORECTUM}

QUESTION: does periodic examination of the colorectum lead to early detection of FAP and reduction of CRC-associated mortality?

A literature search showed that at least five studies have addressed the first part of the question. ${ }^{15-19}$ These studies decribed the results of polyposis registers that were established in various countries mostly in the 1980s and 1990s in order to improve the prognosis of patients with this disease. All studies showed that in symptomatic FAP cases, the incidence of CRC was much higher (incidence: $50-70 \%$ ) than in those that were identified by surveillance (incidence: $3-10 \%$ ) initiated by the registries. Other studies that evaluated the mortality of patients with FAP reported that surveillance policies and prophylactic colectomy have resulted in a reduction in the number of FAP patients that died from CRC but that, nowadays, a greater proportion of deaths is attributable to extracolonic manifestations of the disease (desmoid tumours, duodenal cancer) ${ }^{20-22}$ At least three studies have indicated that central registration and prophylactic examination led to a reduction of CRC-associated mortality. ${ }^{23-25}$

CONCLUSION: surveillance of FAP patients leads to reduction of $C R C$ and CRC-associated mortality (category of evidence III).

QUESTION: what is the optimal surveillance protocol in terms of timing, type of investigation and surveillance interval in patients with classical FAP and AFAP?

\section{Classical (typical) FAP}

The age at which screening should start depends on the risk of malignant transformation of the colorectal adenomas. ${ }^{26}$ In the recent literature there are no studies that provide information on the distribution of the ages at diagnosis of CRC in FAP because most cases are currently diagnosed in a premalignant stage. Studies on large series of FAP families from the 1970s and 1980s indicated that the risk of developing CRC before age 20 is very low. ${ }^{16}$ The proportion of FAP patients with CRC diagnosed at $\leqslant 20$ years of age observed in some European registries is shown in table 3.

There were no cases of CRC at or before the age of 10 years, and an incidental case between age 11 and 15 years. Based on these findings, the European group advises starting endoscopic surveillance from the early teens. Since some patients, especially those with a mutation located at codon 1309 in the APC gene (see below), may develop severe polyposis of the colorectum before the age of 10, attention must be paid to FAP-related symptoms. ${ }^{27}$ These symptoms may include increasing bowel 
Table 3 Proportion of FAP patients with CRC diagnosed at $\leqslant 20$ years of age*

\begin{tabular}{lclcc}
\hline & & \multicolumn{2}{l}{ Number of CRCs (\%) diagnosed } \\
\cline { 4 - 5 } Polyposis registry & Total number of CRCs & $\mathbf{0 - 1 0}$ years & $\mathbf{1 1 - 1 5}$ years & $\mathbf{1 6 - 2 0}$ years \\
\hline The Netherlands & 106 & 0 & 1 & 1 \\
Denmark & 190 & 0 & 0 & 3 \\
Germany & 524 & 0 & 1 & 7 \\
St Mark's & 96 & 0 & 0 & 3 \\
Finland & 157 & 0 & 0 & 1 \\
Total & 1073 & 0 & $2(0.2 \%)$ & $15(1.3 \%)$ \\
\hline
\end{tabular}

${ }^{*}$ Communicated with registries.

$\mathrm{CRC}$, colorectal cancer, FAP, familial adenomatous polyposis.

movements, looser stools, mucous discharge, rectal bleeding, abdominal or back pain. In symptomatic patients, endoscopic investigation may be indicated at any age.

In family members with an identified mutation, endoscopic surveillance should be continued lifelong because the penetrance of the disease is virtually $100 \%$. In high risk members (first-degree relatives of affected patients) from families without an identified APC mutation, surveillance should be continued until age 50 .

The second question is which part of the colorectum should be investigated. Only one study was found that specifically addressed this question. In that study, Bussey demonstrated that in 170 patients with FAP, the rectum was affected in all cases. ${ }^{16}$ Based on these studies it is sufficient to perform flexible sigmoidoscopy, at least initially. Once adenomas are identified with sigmoidoscopy, there is an indication for full colonoscopy.

Regarding the interval between examinations, studies on the natural history of FAP showed that it takes on average 15-20 years from the first development of adenomas to the development of malignancy. ${ }^{16}$ Therefore, an interval of 2 years between normal sigmoidoscopies is appropriate. If adenomas are detected, colonoscopic investigations should be performed annually until colectomy is planned. In high risk members (first-degree relatives of affected patients) from families without an identified APC mutation, surveillance should be continued at 2 -yearly intervals until age 40. After this age the intervals between examinations may be longer-for example, every 3-5 years-and surveillance may be discontinued at age 50 .

\section{AFAP}

In families with AFAP, a different protocol is recommended. A recent Dutch study on nine AFAP families associated with APC mutation reported a mean age at diagnosis of CRC of 54 years $(\mathrm{n}=40)$ which is about $10-15$ years later than in classical FAP. No cases of CRC were observed in individuals younger than 20 years. The youngest case of CRC was diagnosed at age 24 years. ${ }^{4}$ In an American study of a large family with AFAP, no CRC was observed in patients under the age of 29 years. ${ }^{28}$ Therefore, periodic examination is recommended starting from age 18-20. Because patients with AFAP have been described that develop only a few adenomas localised in the right part of the colon, colonoscopy is recommended instead of sigmoidoscopy.
CONCLUSION: the suggested surveillance protocol for patients with classical and attenuated FAP is summarised in table 4 (category of evidence III, grade of recommendation B)

\section{MANAGEMENT OF COLONIC POLYPOSIS}

Removal of the colon with polyposis at a premalignant stage is very important because it prevents the significant morbidity and mortalitiy associated with advanced CRC.

QUESTION: which surgical procedure is the best option for patients with FAP?

The two main options of prophylactic removal of the large intestine are colectomy with ileorectal anastomosis (IRA) and proctocolectomy with ileal pouch-anal anastomosis (IPAA). IRA is a relatively simple and straightforward operation, compared with IPAA. The complication rate is relatively low and the bowel function postoperatively is almost always good. For IPAA, more extensive surgery is needed including pelvic dissection with its risk of haemorrhage, reduction of fertility in women and potential damage to pelvic nerves. ${ }^{29}$ Recently, a meta-analysis by Aziz et al has been published of studies that compared adverse effects, functional outcome and quality of life between the two options. ${ }^{30}$ The authors selected 12 studies containing 1002 patients with FAP. They reported that bowel frequency, night defecation and use of incontinence pads were significantly less in the IRA group, although faecal urgency was more frequent with IRA compared with IPAA. Reoperation within 30 days was more common after IPAA. There was no significant difference between the procedures in terms of sexual dysfunction, dietary restriction or postoperative complications. Rectal cancer was only observed in the IRA group (5\%). In addition, abdominal reoperation on the rectum was more frequent after IRA (28\%) versus IPAA (3\%). The study demonstrated the individual merits and weaknesses of IRA and IPAA.

An IPAA is the treatment of choice if the patient has a large number of rectal adenomas-for example more than 15-20 adenomas. In patients with only a few rectal adenomas or with a polyp-free rectum, both options are possible and the decision can be made on an individual basis.

Several studies have shown that the severity of colonic polyposis is correlated with the site of the mutation in the APC

Table 4 Colorectal surveillance protocol in family members at risk for (A)FAP

\begin{tabular}{llll}
\hline & Type of investigation & Lower age limit & Interval \\
\hline Classical FAP & Sigmoidoscopy* & $10-12$ years & 2 years* $^{*}$ \\
AFAP & Colonoscopy & $18-20$ years & 2 years* $^{*}$ \\
\hline
\end{tabular}

*Once adenomas are detected annual colonoscopy should be performed until colectomy is planned.

(A)FAP, (attenuated) familial adenomatous polyposis. 
gene. These studies have recently been reviewed by Nieuwenhuis et al. ${ }^{31}$ The evaluation showed that mutations between codons 1250 and 1464, especially those with a mutation at codon 1309, are associated with a severe form of FAP, mutations localised at the extreme ends of the gene and in the alternatively spliced part of exon 9 are associated with a mild from of FAP, and an intermediate expression of disease is found in patients with mutations in the remaining parts of the gene. Several authors have proposed to use the outcome of genetic testing in guiding the surgical treatment of patients with a relatively polyp-free rectum. ${ }^{32-36}$ An IPAA may be advised in patients with a severe genotype because such patients are at increased risk of developing severe rectal polyposis that will require a secondary proctectomy if IRA is performed. ${ }^{33-35}$ An IRA is indicated in those with a mild genotype because of the low risk of developing severe rectal polyposis. ${ }^{35}{ }^{36}$ However, a consensus has not yet been reached by the Mallorca group, or more widely, on use of genotype as a decision aid to guide the choice of IRA or IPAA in patients with FAP who have no or little evidence of rectal polyposis. ${ }^{37}$

Other factors that should be taken into account are fertility and desmoid development. Studies reported that fertility was significantly reduced after IPAA compared with IRA in women with FAP. ${ }^{38}$ Therefore, in young women who wish to have children, an IPAA should be avoided or postponed, if possible. In patients with desmoids it has been reported that conversion of IRA to IPAA might be difficult due to (asymptomatic) mesenteric desmoid tumours and shortening of the mesentery. For this reason, a primary IPAA might be the best option in patients with an increased risk of desmoid development-for example, patients with a positive family history for these tumours or patients with a mutation located distal to codon 1444. Some members of the Mallorca group noted, however, that patients with mutations $3^{\prime}$ of 1444 often have mild polyposis, and performing an IPAA might be overtreatment.

In conclusion, the decision on the type of surgery depends on many factors. It should be emphasised that the final decision on the type of surgery lies with the patient after being fully informed about the natural history of the disease and the pros and cons of the main surgical options.

There are no guidelines regarding the timing of surgery. In general, a (procto)colectomy is indicated if there are large numbers of adenomas $>5 \mathrm{~mm}$, including adenomas showing a high degree of dysplasia. Most patients with classical FAP undergo surgery between age 15 and 25 years.

The frequency of endoscopic follow-up of the rectum after IRA depends on the severity of rectal polyposis. The

Table 6 The progression of duodenal polyposis in familial adenomatous polyposis

\begin{tabular}{llll}
\hline Author & Groves & Saurin & Bulow \\
\hline Year of publication & 2002 & 2004 & 2004 \\
Subjects & 99 & 35 & 368 \\
Mean age (years) & 42 & 37 & 25 \\
Sex (\% male) & 55 & 57 & 49 \\
Mean follow-up (years) & 10 & 4 & 7.6 \\
Spigelman stage IV & & & \\
$\quad$ at initial examination & $9.6 \%$ & $14 \%$ & $7 \%$ \\
$\quad$ at last follow-up & $14 \%$ & $35 \%$ & $15 \%$ \\
Duodenal cancer during follow-up & $6 *$ & 0 & $4 \dagger$ \\
\hline
\end{tabular}

*Spigelman stage at previous endoscopy: II, III, IV, IV, IV, IV.

$\dagger$ Spigelman stage at previous endoscopy: II, III, IV, IV.
Table 5 Spigelman classification for duodenal polyposis in familial adenomatous polyposis

\begin{tabular}{llll}
\hline Criterion & 1 point & 2 points & 3 points \\
\hline Polyp number & $1-4$ & $5-20$ & $>20$ \\
Polyp size $(\mathrm{mm})$ & $1-4$ & $5-10$ & $>10$ \\
Histology & Tubular & Tubulovillous & Villous \\
Dysplasia & Mild $^{*}$ & Moderate $^{*}$ & Severe $\dagger$ \\
\hline
\end{tabular}

Stage 0, 0 points; stage I, 1-4 points; stage II, 5-6 points; stage III, 7-8 points; stage IV, 9-12 points.

${ }^{*}$ A low degree of dysplasia according to current classification.

$\dagger$ A high degree of dysplasia.

recommended interval varies between 3 and 6 months. In patients with multiple large $(>5 \mathrm{~mm})$ rectal adenomas that show a high degree of dysplasia there is an indication for proctectomy. Because patients with IPAA may also develop adenomas and even cancer in the pouch, follow-up is indicated after this procedure at intervals of 6-12 months. ${ }^{39-42}$

CONCLUSION: the main surgical options of removal of the colorectum - that is, total colectomy with ileorectal anastomosis (IRA) and proctocolectomy with ileal pouch-anal anastomosis (IPAA) - both have their individual merits and weaknesses. The decision on the type of colorectal surgery in patients with FAP depends on many factors including the age of the patient, the severity of rectal (and colonic) polyposis, the wish to have children, the risk of developing desmoids and possibly the site of the mutation in the APC gene. The final decision lies with the patient after being fully informed about the natural history of the disease and the pros and cons of the available surgical options. The group advises that IPAA should preferably be performed in expert centres.

\section{SURVEILLANCE OF THE DUODENUM}

Many studies have shown that adenomas in the duodenum can be found in $50-90 \%$ of cases. ${ }^{43}{ }^{44}$ Age appears to be the most important risk factor. There is no clear association between site of the mutation and development of (severe) duodenal polyposis. In most studies, the severity of duodenal polyposis is assessed using the Spigelman classification. ${ }^{45}$ This system describes five (O-IV) stages (table 5). Points are accumulated for number, size, histology and severity of dysplasia of polyps. Stage I (1-4 points) indicates mild disease, whereas stage III-IV ( $>6$ points) implies severe duodenal polyposis. Approximately $80 \%$ of the patients have stage I-III disease and $10-20 \%$ have stage IV disease.

QUESTION: does periodic examination of the upper gastrointestinal tract lead to detection of duodenal polyposis in an early stage?

There are three prospective studies of surveillance of the duodenum (table 6). ${ }^{44} 46$ These studies demonstrated slow progression of duodenal polyps in size, number and histology. The risk of developing cancer appears to be related to the Spigelman stage. In the British study, ${ }^{46} 4$ out of 11 patients with stage IV disease at initial examination developed cancer, as did one out of 41 patients with initially stage III disease. In the Scandinavian-Dutch study, ${ }^{44} 2$ out of 27 patients with stage IV disease at the first endoscopy developed cancer compared with 2 out of $339(<1 \%)$ with stage 0 -III. The cumulative risk of duodenal cancer at age 57 was $4.5 \%$.

CONCLUSION: prospective follow-up studies on the natural history of duodenal polyposis have demonstrated that the adenomas progress slowly to cancer. Because the conversion from adenomas to carcinoma may take more than 15-20 years, current screening protocols of the upper gastrointestinal tract usually detect duodenal disease at a premalignant stage (category of evidence III). 


\section{MANAGEMENT OF DUODENAL POLYPOSIS}

QUESTION: does treatment of premalignant duodenal lesions lead to a reduction of mortality related to duodenal cancer?

In the literature, there are no studies in which surveillance and treatment of duodenal disease is compared with a strategy of no surveillance. Although the overall risk of developing duodenal cancer in all patients with FAP is relatively low $(\sim 5 \%),{ }^{11}$ the risk of developing cancer in patients with Spigelman stage III-IV duodenal adenomatosis is much higher (7-36\%). ${ }^{44}{ }^{46}$ Identification of such patients is important because particularly this category of patients might benefit from intensive surveillance and early treatment.

The options of treatment are endoscopic and surgical. Endoscopic treatment includes snare excision, thermal ablation, argon plasma coagulation or photodynamic therapy. There are only a few studies that evaluated the outcome of endoscopic treatment. These studies have recently been reviewed by Brosens et al. ${ }^{48}$ The review demonstrated that the recurrence rate of adenoma development after endoscopic treatment is high $(>50 \%)$ and that the treatment is associated with a high complication rate (perforation, haemorrhage, pancreatitis) $(17 \%)$.

There is no consensus about how to treat patients with duodenal polyposis. In patients with only a few small adenomas (Spigelman stage I and II), the risk of developing duodenal cancer is very low and, in view of the potential serious complications associated with (endoscopic) treatment, the management may be limited to follow-up.

In patients with multiple larger adenomas (Spigelman stage III or more), the risk of duodenal cancer is higher. Because it is impossible to remove all adenomas, an appropriate approach might be to remove only large adenomas-for example, those of $>1 \mathrm{~cm}$ in diameter-or adenomas with a high degree of dysplasia. However, duodenal adenomas are usually flat and therefore difficult to remove. For these cases prior submucosal saline/adrenaline injection may facilitate removal and reduce the risk of haemorrhage and perforation. Although the value of endoscopic treatment of patients with stage II and III is unknown, a possible advantage of endoscopic treatment is that it may delay major intervention (eg, Whipple's procedure) which is associated with a significant morbidity (20-30\%) and even mortality. The Mallorca group advises centralisation of such treatment in a few expert centres.

The options for surgical treatment of duodenal polyposis in FAP include local surgical treatment (duodenotomy with polypectomy and/or ampullectomy), pancreas-sparing duodenectomy and (pylorus-sparing) pancreaticoduodenectomy (Whipple's procedure). At least 11 studies, also reviewed by Brosens et al, evaluated the outcome of local treatment of duodenal polyposis. ${ }^{48}$ Most studies reported a high recurrence rate after local surgery in FAP patients with severe polyposis. The most important advantage of this treatment is that it may postpone major surgery in young patients. Duodenotomy might be especially useful in patients with one or two dominant worrisome duodenal lesions in an otherwise minimally involved intestine.

In patients with stage IV disease found at repeated endoscopic examinations, there is an indication for pancreaticoduodenectomy or a pancreas-sparing duodenectomy. Brosens et al identified 12 studies that evaluated the outcome of this treatment. All studies showed that the recurrence rate of adenomas (in the proximal small bowel) was relatively low. However, in order to be able to investigate this part of the small bowel after surgery, the Roux-Y should be constructed in such a
Table 7 Recommended surveillance interval between upper gastrointestinal endoscopic examination in relation to Spigelman classification

\begin{tabular}{ll}
\hline Spigelman classification & Surveillance interval (years) \\
\hline O/I & 5 \\
II & 3 \\
III & $1-2$ \\
IV & Consider surgery \\
\hline
\end{tabular}

way that endoscopic follow-up is possible. The specific choice of procedure depends on the local expertise.

CONCLUSION: screening of the duodenum in patients with FAP may lead to the identification of patients with advanced duodenal disease (Spigelman stage III/IV). Intensive surveillance and treatment of such patients may lead to reduction of duodenal cancer-related mortality (category of evidence III/IV). In young patients ( $<40$ years) with advanced disease (stage III/IV), local surgery (duodenotomy and polypectomy) might be of benefit to postpone major surgery. In older patients with stage IV disease at repeated examinations, there is an indication for duodenectomy (category of evidence $I V$, grade of recommendation $C$ ).

QUESTION: what is the appropriate protocol in terms of timing, type of investigation and surveillance interval?

There is no consensus in the literature regarding the age at which upper gastrointestinal tract surveillance should be initiated. Some authors advise to start at the diagnosis of FAP, others from the age of 25-30 years. Evaluation of all cases of duodenal cancer reported in the literature showed that diagnosis before age 30 years is extremely rare. ${ }^{48}$ Therefore, the Mallorca group recommends to start from an age between 25 and 30 years. Most centres recommend the use of a side-viewing endoscope to allow detailed inspection of the papilla, the predelicted site for duodenal polyposis. However, in the early Spigelman stages, the use of a forward-viewing endoscope might also be appropriate. The recommended intervals between screening depend on the severity of disease (table 7). ${ }^{44} 46$

CONCLUSION: the Mallorca group recommends that surveillance of the upper gastrointestinal tract be initiated between age 25 and 30 years. The suggested protocol is shown in table 7 (category of evidence IV, grade of recommendation C).

\section{MANAGEMENT OF DESMOID TUMOURS}

QUESTION: what is the appropriate treatment of desmoid tumours?

A substantial number of FAP patients (at least 10-15\%) develop desmoid tumours. Possible risk factors include abdominal surgery, positive family history for desmoids and site of the mutation (mutations beyond codon 1444). ${ }^{14}{ }^{49-51}$ In contrast to sporadic desmoid tumours, the majority of the tumours associated with FAP are located in the abdominal wall or intra-abdominally. The tumours can be diagnosed by CT scanning or MRI. The latter procedure may also provide information on the activity of the tumour. Desmoid tumours are also frequently encountered incidentally in patients requiring further surgery. The options for treatment are pharmacological treatment (non-steroidal anti-inflammatory drugs (NSAIDs) and/or anti-oestrogens), chemotherapy, surgical excision or radiotherapy. ${ }^{52-54}$ Evidence for the efficacy of these treatments is poor and is based on small, non-controlled studies. An additional problem for the evaluation of efficacy is that desmoids have a variable natural history, with some tumours showing spontaneous regression in the absence of treatment. 
In 2003, Janinis et al performed a systematic review of published clinical trials, studies and case series that reported the effectiveness of pharmacological treatment of desmoid tumours. ${ }^{55}$ The authors concluded that the evidence in the literature supports the opinion that both non-cytotoxic and cytotoxic chemotherapies are effective against desmoid tumours. However, the lack of sufficient patient numbers and randomised trials compromises the validity of the reported results and mandates further investigation with prospective studies including larger patient numbers.

In 2000, a review of the literature was published on the effectiveness of surgery compared with radiation therapy for (non-FAP) patients with desmoid tumours. ${ }^{56}$ The study showed that radiation therapy alone or in combination with surgery resulted in significantly better control than surgery.

Currently, the first line of treatment in patients with large or growing intra-abdominal or abdominal wall tumours is sulindac (300 mg) usually in combination with tamoxifen (40-120 mg) or toremifene $(180 \mathrm{mg})$. $^{52-54} 57$ In patients with progressive intraabdominal tumours that do not respond to this treatment, chemotherapy (eg, doxorubicine and dacarbazine or methotrexate and vinblastine $)^{58}{ }^{59}$ or radiation therapy is indicated. The preferred treatment of patients with an abdominal wall desmoid tumour is controversial. Some authors consider surgery of abdominal wall desmoid tumours as a reasonable first-line treatment in these cases. ${ }^{54}$ Others do not recommend surgery as primary treatment because most especially large tumours cannot be resected and the recurrence rate is high. ${ }^{60}$ There is also no agreement about the role of surgery for mesenteric desmoids. Some investigators consider surgery contraindicated because of the risk of severe complications (short bowel syndrome, severe bleeding) or because surgery may trigger further growth of the tumour. ${ }^{52} 60$ These investigators recommend only minimal surgery (intestinal bypass) in patients with obstruction or advise stenting of the ureter in patients with ureteric involvement. Others, however, reported succesful excision of large mesenteric desmoids with low mortality and limited loss of the small bowel, ${ }^{61}{ }^{62}$ and consider that resection of mesenteric desmoids in experienced hands may have a role in the treatment of selected patients unresponsive to conservative treatment

CONCLUSION: non-randomised, non-controlled studies suggest that sulindac in combination with tamoxifen is effective in FAP patients with intra-abdominal desmoids and desmoids located at the abdominal wall (category of evidence III). Also small non-controlled studies indicate that chemotherapy or radiotherapy may be of benefit in those with progressive growing desmoids (category of evidence III).

The role of surgery of (intra)-abdominal-(wall) tumours is controversial (category of evidence III)

\section{PHARMACOLOGICAL TREATMENT}

QUESTION: what is the role of NSAIDS in the treatment of colorectal and duodenal adenomas in FAP?

The first drug that was shown to be effective in FAP was sulindac. ${ }^{63-66}$ Long-term use of this drug reduced the number of colorectal adenomas by $>50 \%$ in the colon as well as in the retained rectal segment of FAP patients after initial colectomy. ${ }^{63-67}$ However, sulindac did not prevent development of adenomas in FAP. ${ }^{68}$

In the 1990s, selective COX-2 (cyclo-oxygenase-2) inhibitors were developed that were reported to have fewer (gastrointestinal related) side effects than the classical non-selective NSAIDs. One of these drugs (celecoxib) was found to reduce the number of colorectal adenomas by $28 \%{ }^{69}$ In contrast to sulindac, this drug also reduced the number of duodenal adenomas. ${ }^{70}$ Unfortunately, cardiovascular side effects have recently been reported in patients using another selective COX-2 inhibitor, rofecoxib. In a trial involving 2600 patients with colon polyps, $3.5 \%$ of the patients assigned to rofecoxib had a myocardial infarction or stroke, as compared with $1.9 \%$ of the patients assigned to placebo, necessitating premature cessation of the trial. $^{71}{ }^{72}$ A recently published meta-analysis of different NSAIDs confirmed the increased risk of cardiovascular diseases with rofecoxib. ${ }^{73}$ The analysis included 11 studies that reported on celecoxib. It was found that celecoxib exposure in a dose of around $200 \mathrm{mg}$ per day did not lead to an elevation of the risk of cardiovascular disease, but the data did not exclude an increased risk with higher doses which are usually indicated in FAP. Celecoxib (onsenal) is registered for the treatment of FAP in several countries, but some specialists who are dealing with the management of FAP patients are reluctant to prescribe these drugs, especially because most patients have to use the drug in high doses on a long-term basis. Data are currently being collected on a worldwide basis to evaluate the effect and possible side effects of the long-term use of celecoxib in patients with FAP.

Although NSAIDs do not replace surgical treatment for colonic FAP, they may yet play a role in postponing surgery in patients with mild colonic polyposis or patients with rectal polyposis after prior colectomy. They may also be used in patients who refuse surgical treatment or in patients that cannot be operated on because of extensive desmoid disease. Although the effect of celecoxib on the number of colorectal adenomas has never been directly compared with the effect of sulindac, the published trials suggest a stronger effect of the latter. In addition, an association of sulindac with serious cardiovascular side effects has never been reported, and the gastrointestinal-related toxicity can be treated with proton pump inhibitors if necessary. Based on these considerations, one may argue that sulindac is more attractive than celecoxib for the treatment of colorectal adenoma.

Regarding the treatment of duodenal polyposis, the use of celecoxib might be justifiable for patients with severe duodenal polyposis (Spigelman stage III or IV), because the endoscopic and surgical treatment options in such cases are associated with significant complications.

CONCLUSION: chemoprevention with NSAIDs can be considered in patients following initial prophylactic surgery as an adjunct to endoscopic surveillance, to reduce the rectal polyp burden. The role of selective COX-2 inhibitors in patients with FAP is controversial because of cardiovascular side effects reported for rofecoxib. Therefore, these drugs should only be considered in selected patients without cardiovascular risk factors until more data are available.

\section{MUTYH-ASSOCIATED ADENOMATOUS POLYPOSIS (MAP)}

In 2002, Al-Tassan et al demonstrated a role for defective base excision repair (BER) in hereditary colorectal cancer. ${ }^{5}$ They identified bi-allelic germline mutations in the BER gene MUTYH in a British family with three affected members and recesssive inheritance of multiple colorectal adenomas and carcinoma. Further studies found bi-allelic MUTYH mutations in 26-29\% of patients with 10-100 polyps and 7-29\% of patients with 1001000 polyps. $^{74-76}$ Bi-allelic mutations have rarely been reported in patients with fewer than 10 adenomas, and in some apparently CRC-only patients. ${ }^{77} 78$ Based on these findings, patients with more than 10 adenomas should be referred for genetic counselling, and mutation analysis of the MUTYH gene should be considered. Bi-allelic MUTYH mutations are usually 
associated with an attenuated polyposis phenotype. To date, other intestinal malignancies and FAP-associated extraintestinal lesions such as duodenal cancer, osteomas and CHRPE (congenital hypertrophy of the retinal pigment epithelium) have been reported only sporadically in MAP patients. ${ }^{79} 80$ Family members with mono-allelic mutations in MUTYH are probably not at increased risk of CRC, and therefore do not need colonoscopic surveillance. ${ }^{81}$

QUESTION: which surveillance protocol should be recommended to patients with FAP due to bi-allelic MUTYH mutations?

The decision regarding the age at which screening should start is based on the distribution of ages at diagnosis of CRC. CRC due to bi-allelic MUTYH mutations before the age of 30 years has been reported only once. ${ }^{79}$ Therefore, it appears justified to start screening from the same age as recommended in AFAP (between 18 and 20 years). Because patients may develop only a few adenomas and CRC is often localised in the proximal part of the colon, the Mallorca group recommend performing colonoscopy at 2-yearly intervals instead of sigmoidoscopy. Upper gastrointestinal endoscopy is advised starting from between 25 and 30 years of age. The recommended intervals between screening depend on the severity of disease (table 7).

CONCLUSION: the suggested surveillance protocol for MAP patients is similar to that for patients with AFAP (category of evidence III, grade of recommendation $B$ ) (see table 4).

QUESTION: what is the approprate surgical treatment of colonic polyposis in carriers of bi-allelic MUTYH mutations?

Most patients with bi-allelic MUTYH mutations have an attenuated phenotype. ${ }^{7679}$ Because of the small number of adenomas, in some patients it is possible to remove these polyps endoscopically. If surgery is required, an IRA will be sufficient in most cases to eliminate the cancer risk. However, if rectal polyposis is severe, an IPAA is advised.

\section{DISCUSSION}

The guidelines for the management of FAP presented here are the result of intensive discussions among the participants of two workshops held in Mallorca in 2006 and 2007. Because most of the studies that form the basis for the guidelines were descriptive and/or retrospective in nature, many of the recommendations were based on expert opinion.

The identification of a mutated APC gene as the cause of FAP in the early 1990s allowed presymptomatic diagnosis in families with an identified mutation. As a consequence, those individuals that were found not to carry the mutation could be reassured and surveillance could be discontinued. Another way in which genetic information might be translated into clinical practice is in the decision-making process of surgical treatment. Studies have shown that the site of the mutation in the APC gene may predict the risk of developing severe rectal polyposis and the need for subsequent proctectomy if a patient had colectomy with IRA. Using this genetic information, individuals may be identified with a low or high risk of developing significant rectal polyposis, and this can help in the decision between IRA and IPAA in difficult cases. However, the use of genetic information in the surgical decision making is controversial, because several studies have reported intrafamilial variation, which might be due to environmental factors or modifier genes. Moreover, in many patients, a previously unknown (private) mutation is identified which cannot be used to predict the future course of the colorectal phenotype. Therefore, future prospective studies should be done to evaluate the utility of this genetic information in surgical practice.
In undiagnosed cases of FAP, the leading cause of death is colorectal cancer. The establishment of registries of FAP families worldwide has encouraged participation in surveillance programmes and has significantly reduced death from CRC. Nowadays, the prognosis of FAP patients appears to be increasingly determined by extracolonic features of FAP, especially duodenal cancer and desmoid tumours. Future studies should therefore focus on how the management of these tumours can be improved.

Regarding duodenal polyposis, a few prospective studies have shown that the Spigelman classification can be used to identify patients who are at high risk of developing duodenal cancer. However, the risk of developing duodenal cancer reported for patients with Spigelman stage IV varied greatly between these studies. Therefore, additional risk factors should be sought which can predict the development of duodenal cancer more precisely. The knowledge of such risk factors may also be helpful in decisions regarding the choice between local (endoscopic or surgical) treatment or a more definitive treatment such as duodenectomy. Ideally, the latter option should be reserved for those patients with a high risk of developing duodenal cancer, while local treatment may be indicated in those with a low risk.

All studies on the efficacy of drugs for desmoid tumours have been small and non-controlled. Therefore, randomised controlled trials are needed to evaluate the effectiveness of the drugs that are currently used. Several studies have shown that surgery for colonic polyposis constitutes a risk factor for development of desmoid tumours. Future studies should address whether prophylactic treatment with sulindac and tamoxifen for 6 or 12 months postoperatively decreases the risk of desmoid tumours, especially in those patients with an increased risk of desmoids.

A possible way to improve the prognosis of patients with FAP further is early detection and treatment of the less common extraintestinal cancers which are seen with increased frequency in individuals with FAP (see table 2). It has been reported that female FAP patients have a $2-3 \%$ lifetime risk of developing thyroid cancer. ${ }^{82}$ Based on these figures, some investigators have recommended surveillance of the thyroid by palpation and ultrasound, especially in women with FAP. ${ }^{83}$ However, other investigators consider the risk too low to justify such a programme. ${ }^{85}$ Surveillance for hepatoblastoma is also controversial. The risk for these tumours is about $1 \%$, and most tumours develop in the first year of life, with a predominance in males. ${ }^{86}$ Future studies should evaluate whether surveillance programmes for thyroid cancer and hepatoblastoma in FAP are effective and whether any gain in life expectancy outweighs the potential psychosocial problems that may result. ${ }^{87}$ Small bowel cancers located distal to the ligament of Treitz have occasionaly been reported in FAP. In view of the development of new techniques for visualisation of the small bowel (videocapsule endoscopy, double balloon endoscopy) in recent years, the question arises of whether surveillance of the small bowel might be useful. In order to answer this question, studies are needed that evaluate the lifetime risk of developing such tumours.

The ideal treatment of patients with FAP would be pharmacological. Several studies have shown sulindac to be effective in reducing colorectal adenomas. Celecoxib is the only drug that has been shown to be effective in reducing duodenal adenomatosis. In view of the serious cardiovascular side effects that have been reported in patients using one of the other selective COX-2 inhibitors (rofecoxib), some specialists are reluctant to prescribe celecoxib. However, provided that 


\section{SUMMARY}

- Surveillance of FAP patients leads to reduction of CRC and CRC-associated mortality.

- The decision on the type of colorectal surgery in patients with FAP depends on the age of the patient, the severity of rectal polyposis, the wish to have children, the risk of developing desmoids and possibly the site of the mutation in the APC gene. The final decision lies with the patient after being fully informed about the pros and cons of the surgical options.

- Prospective follow-up studies on the natural history of duodenal polyposis have demonstrated that the adenomas progress slowly to cancer. Current screening protocols of the upper gastrointestinal tract usually detect duodenal disease at a premalignant stage.

- In young patients ( $<40$ years) with advanced duodenal disease (Spigelman stage III/IV), local surgery (duodenotomy and polypectomy) might be of benefit to postpone major surgery. In older patients with stage IV disease at repeated examinations, there is an indication for duodenectomy.

- Studies suggest that sulindac in combination with tamoxifen is effective in FAP patients with intra-abdominal desmoids and desmoids located at the abdominal wall. Other studies indicate that chemotherapy or radiotherapy may be of benefit in those with progressive growing desmoids.

- Chemoprevention with NSAIDs can be considered in patients following initial prophylactic surgery as an adjunct to endoscopic surveillance, to reduce the rectal polyp burden. The role of selective COX-2 inhibitors in patients with FAP is controversial.

- The suggested surveillance protocol for MUTYH-associated FAP (MAP) patients is similar to that for patients with AFAP.

patients are screened for cardiovascular risk factors, the use of COX-2 inhibitors may be justifiable in special situations-for example, in patients with severe duodenal polyposis (Spigelman III and IV). Future studies should evaluate whether the potential risk of cardiovascular side effects of celecoxib is significant in view of the possible use of these agents to reduce the cancer risk and avoid the morbidity and mortality associated with the endoscopic and surgical treatment for duodenal polyposis.

Finally, it has to be taken into account that although NSAIDs have been shown to reduce the number of adenomas, it has never been proven that these drugs also prevent the development of CRC. This is an important question because patients have been reported that developed cancer whilst being treated with NSAIDs, despite showing reduction of the size and number of rectal adenomas. ${ }^{88}$

In conclusion, the guidelines described here may be helpful in the appropriate management of families with FAP. In order to improve further the care of these families, there is an urgent need for prospective controlled studies. The workshops in Mallorca have identified several collaborative studies that the group will focus on to clarify some of the current controversial issues in the clinical management of FAP.

Author affiliations: ${ }^{1}$ Department of Gastroenterology and Hepatology, Leiden University Medical Centre, Leiden, The Netherlands; ${ }^{2}$ Department of Surgery, St Josefs Hospital Bochum-Linden (Helios), Bochum, Germany; ${ }^{3}$ Department of Medical Genetics, Hospital Virgen del Camino, Pamplona, Spain; ${ }^{4}$ Institute of Human Genetics, University of Bonn, Germany; ${ }^{5}$ Danish HNPCC-register, Hvidovre University Hospital, Hvidovre, Denmark; ${ }^{6}$ Department of Surgery, Hospital Tumori, Milan, Italy; ${ }^{7}$ Genetic
Counselling Unit, Prevention and Cancer Control Department, Catalan Institute of Oncology, Barcelona, Spain; ${ }^{8}$ Department of Surgery, Hvidovre University Hospital, Hvidovre, Denmark; ${ }^{9}$ Institute of Human Genetics, Newcastle-upon-Tyne, UK;

${ }^{10}$ Institute Catala D’Oncologia, Barcelona, Spain; ${ }^{11}$ Laboratoire d'Oncogenetique, Groupe Hospitalier Pitié-Salpêtre, Paris; ${ }^{12}$ Institute of Medical Informatics, Statistics and Epidemiology, University of Leipzig, Leipzig, Germany; ${ }^{13}$ Institute of Medical Genetics, School of Medicine, Cardiff University, UK; ${ }^{14}$ Department of Clinical Genetics, Leiden University Medical Centre, The Netherlands; ${ }^{15}$ Department of Clinical Genetics, St George's Hospital, London, UK; ${ }^{16}$ Department of Surgery, Helsinki University Central Hospital, Helsinki, Finland; ${ }^{17}$ Department of Surgery, Jyvaskyla Central Hospital, Jyvaskyla, Finland; ${ }^{18}$ Section of Inherited Cancer, Department of Medical Genetics, Rikshospitalet-Radium Hospitalet Medical Centre, Oslo, Norway;

${ }^{19}$ Department of Gastroenterology and Hepatology, Radboud University Medical Centre, Nijmegen, The Netherlands; ${ }^{20}$ Department of Digestive Surgery, Hospital Saint-Antoine, University Pierre et Marie, Paris, France; ${ }^{21}$ Department of Surgery, St Mark's Hospital, Harrow, Middlesex, UK; ${ }^{22}$ Department of Internal Medicine, Universtiy Hospital, Modena, Italy; ${ }^{23}$ Department of Medical Genetics, Ullevål University Hospital, Oslo, Norway; ${ }^{24}$ Digestive Oncology Unit, Department of Internal Medicine, University Hospital Gasthuisberg, Leuven, Belgium; ${ }^{25}$ CRUK, Family Cancer Group, St Mark's Hospital, Harrow, Middlesex, UK

\section{Competing interests: None.}

Similar guidelines for the management of FAP have been published by a group of 10 centres in the USA (www.nccn.org/professionals)

JS has, through Cardiff University, licensed intellectual property rights for mutations of MUTYH.

\section{REFERENCES}

1. Vasen HF, Moslein G, Alonso A, et al. Guidelines for the clinical management of Lynch syndrome (hereditary non-polyposis cancer). J Med Genet 2007;44:353-62.

2. Bulow S. Results of national registration of familial adenomatous polyposis. Gut 2003; 52:742-6.

3. Cruz-Correa M, Giardiello FM. Familial adenomatous polyposis. Gastrointest Endosc 2003;58:885-94.

4. Nielsen M, Hes FJ, Nagengast FM, et al. Germline mutations in APC and MUTYH are responsible for the majority of families with attenuated familial adenomatous polyposis. Clin Genet 2007; 71:427-33.

5. Al-Tassan $\mathbf{N}$, Chmiel NH, Maynard J, et al. Inherited variants of MYH associated with somatic $\mathrm{G}: \mathrm{C} \rightarrow \mathrm{T}: \mathrm{A}$ mutations in colorectal tumors. Nat Genet 2002;30:227-32.

6. Bisgaard ML, Fenger K, Bulow S, et al. Familial adenomatous polyposis (FAP): frequency, penetrance, and mutation rate. Hum Mutat 1994;3:121-5.

7. Aretz S, Uhlhaas S, Caspari R, et al. Frequency and parental origin of de novo APC mutations in familial adenomatous polyposis. Eur J Hum Genet 2004;12:52-8.

8. Aretz S, Stienen D. Friedrichs N, et al. Somatic APC mosaicism: a frequent cause of familial adenomatous polyposis (FAP). Hum Mutat 2007;28:985-92

9. Hes FJ, Nielsen M, Bik EC, et al. Somatic APC mosaicism: an underestimated cause of polyposis coli. Gut 2008;57:71-6.

10. Knudsen AL, Bisgaard ML, Bulow S. Attenuated familial adenomatous polyposis (AFAP). A review of the literature. Fam Cancer 2003:2:43-55.

11. Vasen HF, Bulow S, Myrhoj T, et al. Decision analysis in the management of duodenal adenomatosis in familial adenomatous polyposis. Gut 1997;40:716-9

12. Coffey RJ Jr, Knight CD Jr, van Heerden JA, et al. Gastric adenocarcinoma complicating Gardner's syndrome in a North American woman. Gastroenterology 1985;88:1263-6.

13. Park JG, Park KJ, Ahn YO, et al. Risk of gastric cancer among Korean familial adenomatous polyposis patients. Report of three cases. Dis Colon Rectum 1992;35:996-8.

14. Gurbuz AK, Giardiello FM, Petersen GM, et al. Desmoid tumours in familial adenomatous polyposis. Gut 1994;35:377-81.

15. Alm T. Surgical treatment of hereditary adenomatosis of the colon and rectum in Sweden during the last 20 years. Part II. Patients with prophylactic operations, primary and late results. Discussion and summary. Acta Chir Scand 1975;141:228-37.

16. Bussey HJ. Familial polyposis coli. Baltimore: The John Hopkins University Press, 1975.

17. Bulow S. Clinical features in familial polyposis coli. Results of the Danish Polyposis Register. Dis Colon Rectum 1986;29:102-7.

18. Jarvinen HJ, Husa A, Aukee $S$, et al. Finnish registry for familial adenomatosis coli. Scand J Gastroenterol 1984;19:941-6.

19. Vasen HF, Griffioen G, Offerhaus GJ, et al. The value of screening and central registration of families with familial adenomatous polyposis. A study of 82 families in The Netherlands. Dis Colon Rectum 1990;33:227-30.

20. Arvanitis $\mathbf{M L}$, Jagelman DG, Fazio $\mathrm{WW}$, et al. Mortality in patients with familial adenomatous polyposis. Dis Colon Rectum 1990;33:639-42.

21. Nugent KP, Spigelman AD, Phillips RK. Life expectancy after colectomy and ileorectal anastomosis for familial adenomatous polyposis. Dis Colon Rectum 1993;36:1059-62

22. Belchetz LA, Berk T, Bapat BV, et al. Changing causes of mortality in patients with familial adenomatous polyposis. Dis Colon Rectum 1996;39:384-7. 
23. Bulow S, Bulow C, Nielsen TF, et al. Centralized registration, prophylactic examination, and treatment results in improved prognosis in familial adenomatous polyposis. Results from the Danish Polyposis Register. Scand J Gastroenterol 1995; 30:989-93.

24. Bertario L, Presciuttini S, Sala P, et al. Causes of death and postsurgical survival in familial adenomatous polyposis: results from the Italian Registry. Italian Registry of Familial Polyposis Writing Committee. Semin Surg Oncol 1994;10:225-34.

25. Heiskanen I, Luostarinen T, Jarvinen HJ. Impact of screening examinations on survival in familial adenomatous polyposis. Scand J Gastroenterol 2000;35:1284-7.

26. Vasen HF. When should endoscopic screening in familial adenomatous polyposis be started? Gastroenterology 2000;118:808-9.

27. Distante S, Nasioulas S, Somers GR, et al. Familial adenomatous polyposis in a 5 year old child: a clinical, pathological, and molecular genetic study. J Med Genet 1996;33:157-60.

28. Burt RW, Leppert MF, Slattery ML, et al. Genetic testing and phenotype in a large kindred with attenuated familial adenomatous polyposis. Gastroenterology 2004:127:444-51.

29. Kartheuser A, Stangherlin P, Brandt D, et al. Restorative proctocolectomy and ileal pouch-anal anastomosis for familial adenomatous polyposis revisited. Fam Cancer 2006;5:241-60.

30. Aziz 0, Athanasiou T, Fazio VW, et al. Meta-analysis of observational studies of ileorectal versus ileal pouch-anal anastomosis for familial adenomatous polyposis. Br J Surg 2006;93:407-17.

31. Nieuwenhuis MH, Vasen HF. Correlations between mutation site in APC and phenotype of familial adenomatous polyposis (FAP): a review of the literature. Crit Rev Oncol Hematol 2007:61:153-61.

32. Vasen HF, van der Luijt RB, Slors JF, et al. Molecular genetic tests as a guide to surgical management of familial adenomatous polyposis. Lancet 1996;348:433-5.

33. Wu JS, Paul P, McGannon EA, et al. APC genotype, polyp number, and surgical options in familial adenomatous polyposis. Ann Surg 1998;227:57-62.

34. Bertario L, Russo A, Radice P, et al. Genotype and phenotype factors as determinants for rectal stump cancer in patients with familial adenomatous polyposis. Hereditary Colorectal Tumors Registry. Ann Surg 2000;231:538-43.

35. Nieuwenhuis MH, Mathus-Vliegen LM, Slors FJ, et al. Genotype-phenotype correlations as a guide in the management of familial adenomatous polyposis. Clin Gastroenterol Hepatol 2007:5:374-8.

36. Bulow C, Vasen $\mathrm{H}$, Jarvinen $\mathrm{H}$, et al. lleorectal anastomosis is appropriate for a subset of patients with familial adenomatous polyposis. Gastroenterology 2000;119:1454-60

37. Friedl W, Caspari R, Sengteller M, et al. Can APC mutation analysis contribute to therapeutic decisions in familial adenomatous polyposis? Experience from $680 \mathrm{FAP}$ families. Gut 2001;48:515-21.

38. Olsen KO, Juul S, Bulow S, et al. Female fecundity before and after operation for familial adenomatous polyposis. Br J Surg 2003;90:227-31.

39. Wu JS, McGannon EA, Church JM. Incidence of neoplastic polyps in the ileal pouch of patients with familial adenomatous polyposis after restorative proctocolectomy. Dis Colon Rectum 1998:41:552-6.

40. Van Duijvendijk P, Vasen HF, Bertario L, et al. Cumulative risk of developing polyps or malignancy at the ileal pouch-anal anastomosis in patients with familial adenomatous polyposis. J Gastrointest Surg 1999;3:325-30.

41. Parc YR, Olschwang S, Desaint B, et al. Familial adenomatous polyposis: prevalence of adenomas in the ileal pouch after restorative proctocolectomy. Ann Surg 2001;233:360-4

42. Vrouenraets BC, Van DP, Bemelman WA, et al. Adenocarcinoma in the anal canal after ileal pouch-anal anastomosis for familial adenomatous polyposis using a doublestapled technique: report of two cases. Dis Colon Rectum 2004;47:530-4.

43. Heiskanen I, Kellokumpu I, Jarvinen H. Management of duodenal adenomas in 98 patients with familial adenomatous polyposis. Endoscopy 1999;31:412-6.

44. Bulow S, Bjork J, Christensen IJ, et al. Duodenal adenomatosis in familial adenomatous polyposis. Gut 2004;53:381-6

45. Spigelman AD, Williams CB, Talbot IC, et al. Upper gastrointestinal cancer in patients with familial adenomatous polyposis. Lancet 1989;2:783-5.

46. Groves CJ, Saunders BP, Spigelman AD, et al. Duodenal cancer in patients with familial adenomatous polyposis (FAP): results of a 10 year prospective study. Gut 2002:50:636-41.

47. Saurin JC, Gutknecht C, Napoleon B, et al. Surveillance of duodenal adenomas in familial adenomatous polyposis reveals high cumulative risk of advanced disease. $\checkmark$ Clin Oncol 2004;22:493-8.

48. Brosens LA, Keller JJ, Offerhaus GJ, et al. Prevention and management of duodenal polyps in familial adenomatous polyposis. Gut 2005;54:1034-43

49. Caspari R, Olschwang S, Friedl W, et al. Familial adenomatous polyposis: desmoid tumours and lack of ophthalmic lesions (CHRPE) associated with APC mutations beyond codon 1444. Hum Mol Genet 1995;4:337-40.

50. Bertario L, Russo A, Sala P, et al. Genotype and phenotype factors as determinants of desmoid tumors in patients with familial adenomatous polyposis. Int $\mathrm{J}$ Cancer 2001;95:102-7.

51. Sturt NJ, Gallagher MC, Bassett $\mathrm{P}$, et al. Evidence for genetic predisposition to desmoid tumours in familial adenomatous polyposis independent of the germline APC mutation. Gut 2004; 53:1832-6.

52. Clark SK, Phillips RK. Desmoids in familial adenomatous polyposis. Br J Surg 1996:83:1494-504.
53. Knudsen AL, Bulow S. Desmoid tumour in familial adenomatous polyposis. A review of literature. Fam Cancer 2001;1:111-9.

54. Sturt NJ, Clark SK. Current ideas in desmoid tumours. Fam Cancer 2006;5:275-85

55. Janinis J, Patriki M, Vini L, et al. The pharmacological treatment of aggressive fibromatosis: a systematic review. Ann Oncol 2003;14:181-90.

56. Nuyttens JJ, Rust PF, Thomas CR Jr, et al. Surgery versus radiation therapy for patients with aggressive fibromatosis or desmoid tumors: a comparative review of 22 articles. Cancer 2000;88:1517-23.

57. Hansmann A, Adolph C, Vogel T, et al. High-dose tamoxifen and sulindac as first-line treatment for desmoid tumors. Cancer 2004;100:612-20.

58. Gega M, Yanagi H, Yoshikawa R, et al. Successful chemotherapeutic modality of doxorubicin plus dacarbazine for the treatment of desmoid tumors in association with familial adenomatous polyposis. J Clin Oncol 2006;24:102-5.

59. Skapek SX, Ferguson WS, Granowetter L, et al. Vinblastine and methotrexate for desmoid fibromatosis in children: results of a Pediatric Oncology Group Phase II Trial. $J$ Clin Oncol 2007;25:501-6.

60. Moeslein, G. Current ideas in desmoid tumours: invited commentary. Fam Cancer 2006;5:287-288.

61. Heiskanen I, Jarvinen HJ. Occurrence of desmoid tumours in familial adenomatous polyposis and results of treatment. Int J Colorectal Dis 1996;11:157-62.

62. Latchford AR, Sturt NJ, Neale K, et al. A 10-year review of surgery for desmoid disease associated with familial adenomatous polyposis. Br J Surg 2006;93:1258-64.

63. Waddell WR, Loughry RW. Sulindac for polyposis of the colon. J Surg Oncol 1983:24:83-7.

64. Labayle D, Fischer D, Vielh P, et al. Sulindac causes regression of rectal polyps in familial adenomatous polyposis. Gastroenterology 1991;101:635-9.

65. Giardiello FM, Hamilton SR, Krush AJ, et al. Treatment of colonic and rectal adenomas with sulindac in familial adenomatous polyposis. N Engl J Med 1993;328:1313-6.

66. Cruz-Correa M, Hylind LM, Romans KE, et al. Long-term treatment with sulindac in familial adenomatous polyposis: a prospective cohort study. Gastroenterology 2002;122:641-5.

67. Winde G, Schmid KW, Schlegel W, et al. Complete reversion and prevention of rectal adenomas in colectomized patients with familial adenomatous polyposis by rectal low-dose sulindac maintenance treatment. Advantages of a low-dose nonsteroidal anti-inflammatory drug regimen in reversing adenomas exceeding 33 months. Dis Colon Rectum 1995;38:813-30.

68. Giardiello FM, Yang VW, Hylind LM, et al. Primary chemoprevention of familial adenomatous polyposis with sulindac. N Engl J Med 2002;346:1054-9.

69. Steinbach G, Lynch PM, Phillips RK, et al. The effect of celecoxib, a cyclooxygenase 2 inhibitor, in familial adenomatous polyposis. N Engl J Med 2000;342:1946-52.

70. Phillips RK, Wallace MH, Lynch PM, et al. A randomised, double blind, placebo controlled study of celecoxib, a selective cyclooxygenase 2 inhibitor, on duodenal polyposis in familial adenomatous polyposis. Gut 2002;50:857-60.

71. Topol EJ. Failing the public health—rofecoxib, Merck, and the FDA. N Engl J Med 2004:351:1707-9.

72. Baron JA, Sandler RS, Bresalier RS, et al. A randomized trial of rofecoxib for the chemoprevention of colorectal adenomas. Gastroenterology 2006;131:1674-82.

73. McGettigan P, Henry D. Cardiovascular risk and inhibition of cyclooxygenase: a systematic review of the observational studies of selective and nonselective inhibitors of cyclooxygenase 2. JAMA 2006;296:1633-44.

74. Sieber $\mathbf{0 M}$, Lipton L, Crabtree M, et al. Multiple colorectal adenomas, classic adenomatous polyposis, and germ-line mutations in MYH. N Engl J Med 2003:348:791-9.

75. Gismondi V, Meta M, Bonelli L, et al. Prevalence of the Y165C, G382D and 1395delGGA germline mutations of the MYH gene in Italian patients with adenomatous polyposis coli and colorectal adenomas. Int J Cancer 2004;109:680-4.

76. Nielsen M, Franken PF, Reinards TH, et al. Multiplicity in polyp count and extracolonic manifestations in 40 Dutch patients with MYH associated polyposis coli (MAP). J Med Genet 2005;42:e54.

77. Croitoru ME, Cleary SP, Di NN, et al. Association between biallelic and monoallelic germline MYH gene mutations and colorectal cancer risk. J Natl Cancer Inst 2004;96:1631-4.

78. Farrington SM, Tenesa A, Barnetson R, et al. Germline susceptibility to colorectal cancer due to base-excision repair gene defects. Am J Hum Genet 2005;77:112-9

79. Aretz S, Uhlhaas S, Goergens H, et al. MUTYH-associated polyposis: 70 of 71 patients with biallelic mutations present with an attenuated or atypical phenotype. Int J Cancer 2006;119:807-14.

80. Nielsen M, Poley JW, Verhoef $\mathrm{S}$, et al. Duodenal carcinoma in MUTYH-associated polyposis. J Clin Pathol 2006;59:1212-5.

81. Balaguer F, Castellvi-Bel $\mathrm{S}$, Castells $\mathrm{A}$, et al. Identification of MYH mutation carriers in colorectal cancer: a multicenter, case-control, population-based study. Clin Gastroenterol Hepatol 2007:5:379-87.

82. van der Linde K, Vasen HF, van Vliet AC. Occurrence of thyroid carcinoma in Dutch patients with familial adenomatous polyposis. An epidemiological study and report of new cases. Eur J Gastroenterol Hepatol 1998;10:777-81.

83. Cetta F, Olschwang S, Petracci M, et al. Genetic alterations in thyroid carcinoma associated with familial adenomatous polyposis: clinical implications and suggestions for early detection. World J Surg 1998;22:1231-6.

84. Herraiz $\mathbf{M}$, Barbesino G, Faquin W, et al. Prevalence of thyroid cancer in familial adenomatous polyposis syndrome and the role of screening ultrasound examinations. Clin Gastroenterol Hepatol 2007:5:367-73. 
85. Bulow C, Bulow S. Is screening for thyroid carcinoma indicated in familial adenomatous polyposis? The Leeds Castle Polyposis Group. Int J Colorectal Dis 1997:12:240-2.

86. Giardiello FM, Petersen GM, Brensinger JD, et al. Hepatoblastoma and APC gene mutation in familial adenomatous polyposis. Gut 1996;39:867-9.
87. Aretz $\mathbf{S}$, Koch A, Uhlhaas $\mathrm{S}$, et al. Should children at risk for familial adenomatous polyposis be screened for hepatoblastoma and children with apparently sporadic hepatoblastoma be screened for APC germline mutations? Pediatr Blood Cancer 2006;47:811-8.

88. Lynch HT, Thorson AG, Smyrk T. Rectal cancer after prolonged sulindac chemoprevention. A case report. Cancer 1995;75:936-8.

\section{Editor's quiz : GI snapshot}

\section{ANSWER}

From the question on page 672

Features compatible with Crohn's disease were seen at colonoscopy, with "cobblestoning", aphthous ulceration and non-caseating granulomas in the terminal ileum and ascending colon (fig 1). Behçet's disease was excluded given the absence of pathergy and genital ulceration in this case.

The clinical presentation and features on skin biopsy suggest a diagnosis of Crohn's disease-related, bowel-associated dermatosis-arthritis syndrome. Following intravenous hydrocortisone her dysphagia and arthritis rapidly resolved and she was commenced on azathioprine.

Bowel-associated dermatosis-arthritis syndrome (also known as bowel-bypass syndrome) is a rare manifestation of Crohn's disease $^{13} 4$ The disorder is characterised by arthralgia, polyarthritis and vesiculopustular eruptions on the upper limbs and trunk. ${ }^{1-4}$ The skin lesions develop over $24-48 \mathrm{~h}$ and usually resolve spontaneously within 8 days. ${ }^{1}$ They may be recurrent. Biopsy of these lesions classically demonstrates a perivascular and frequently diffuse infiltrate of neutrophils, in the absence of a leucocytoclastic vasculitis. The disorder was originally reported following jejeno-ileal bypass surgery for morbid obesity. ${ }^{2}$ Subsequently, it has been shown to complicate other gastrointestinal pathologies such as inflammatory bowel disease (IBD) and following Billroth 11 gastrectomy. ${ }^{1}$ It is thought to form part of the spectrum of neutrophilic dermatoses associated with IBD, which include pyoderma gangrenosum, pustular eruption of ulcerative colitis and Sweet's syndrome. These varied skin manifestations have overlapping features and may occur simultaneously. ${ }^{5}$ Bowel-associated dermatosis-arthritis syndrome can be distinguished from Sweet's syndrome by the morphology of the rash as well as more rapid resolution of cutaneous lesions, and from pyoderma gangrenosum and pustular eruption by the upper limb distribution and lack of skin ulceration and necrosis. The pathogenesis is unclear but appears to involve circulating immune complexes formed by antibodies to bacterial peptidoglycan. It usually responds

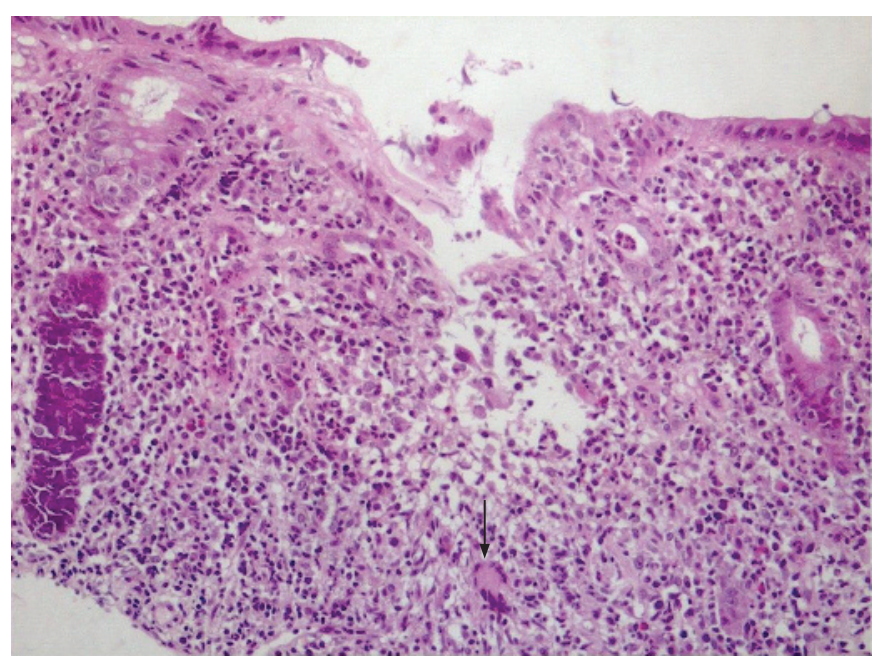

Figure 1 Ascending colonic biopsy showing active Crohn's colitis with crypt abscesses, mucosal erosion, and non-necrotising granulomatous inflammation with a Langhans-type giant cell (arrow).

promptly to antibiotic therapies (tetracycline, sulfamethoxazole/trimethoprim or metronidazole) or corticosteroids.

Gut 2008;57:713. doi:10.1136/gut.2006.117200a

\section{REFERENCES}

1. Jorizzo JL, Apisarnthanarax $\mathrm{P}$, Subrt $\mathrm{P}$, et al. Bowel-bypass syndrome without bowel bypass: bowel-associated dermatosis-arthritis syndrome. Arch Intern Med 1983;143:457-61.

2. Drenick EJ, Ahmed AR, Greenway F, et al. Cutaneous lesions after intestinal bypass. Ann Intern Med 1980;93:557-9.

3. Callen JP. Neutrophilic dermatoses. Dermatol Clin 2002;20:409-19.

4. Boh EE, al-Smadi RM. Cutaneous manifestations of gastrointestinal diseases. Dermatol Clin 2002;20:533-46.

5. Travis S, Innes N, Davies MG, et al. Sweet's syndrome: an unusual cutaneous feature of Crohn's disease or ulcerative colitis. Eur J Gastroenterol Hepatol 1997:9:715-20. 
Guidelines for the clinical management of familial adenomatous polyposis (FAP)

\author{
H F A Vasen, G Möslein, A Alonso, et al.
}

Gut 2008 57: 704-713 originally published online January 14, 2008

doi: $10.1136 /$ gut.2007.136127

Updated information and services can be found at:

http://gut.bmj.com/content/57/5/704.full.html

\begin{tabular}{|c|c|}
\hline \multirow[b]{2}{*}{ References } & These include: \\
\hline & $\begin{array}{l}\text { This article cites } 87 \text { articles, } 22 \text { of which can be accessed free at: } \\
\text { http://gut.bmj.com/content/57/5/704.full.html\#ref-list-1 }\end{array}$ \\
\hline \multirow[b]{2}{*}{$\begin{array}{c}\text { Email alerting } \\
\text { service }\end{array}$} & $\begin{array}{l}\text { Article cited in: } \\
\text { http://gut.bmj.com/content/57/5/704.full.html\#related-urls }\end{array}$ \\
\hline & $\begin{array}{l}\text { Receive free email alerts when new articles cite this article. Sign up in } \\
\text { the box at the top right corner of the online article. }\end{array}$ \\
\hline \multirow{2}{*}{$\begin{array}{r}\text { Topic } \\
\text { Collections }\end{array}$} & Articles on similar topics can be found in the following collections \\
\hline & Colon cancer (2872 articles) \\
\hline
\end{tabular}

Notes

To request permissions go to:

http://group.bmj.com/group/rights-licensing/permissions

To order reprints go to:

http://journals.bmj.com/cgi/reprintform

To subscribe to BMJ go to:

http://group.bmj.com/subscribe/ 